\title{
Evaluation of angiosome based revascularization in diabetic foot ulcers
}

\author{
Sunil Rajendran, Suaib Mohammed Thottiyil, Abid Ali Karatparambil*, Mujeeb Rahman \\ Mohammed Nadakkavil, Ranjish Thamaran, Tom Thomas Kattoor
}

Department of Surgery, Perinthalmanna, Malappuram, Kerala, India

Received: 02 February 2016

Accepted: 08 March 2016

*Correspondence:

Dr. Abid Ali Karatparambil,

E-mail: dr_abid1@yahoo.com

Copyright: $($ ) the author(s), publisher and licensee Medip Academy. This is an open-access article distributed under the terms of the Creative Commons Attribution Non-Commercial License, which permits unrestricted non-commercial use, distribution, and reproduction in any medium, provided the original work is properly cited.

\begin{abstract}
Background: Diabetic foot ulcers are very common complication in diabetic patients and important cause of morbidity to patient and affect quality of life. Ischemia forms a major risk factor for non-healing ulcer. Even after revascularization these ulcers shows delay in healing. Based on studies by Ian Taylor who proposed angiosome concept, it is said that non achievement of direct flow to ulcer area may be a reason for this. Objective of this study was to evaluate the outcome in angiosome based revascularization in diabetic foot ulcer.

Methods: A prospective observational study was done which included 50 diabetic foot ulcer patient who underwent endovascular revascularization in department of general surgery in our hospital during the period October 2013 to March 2015 and they were followed up for 6 months to look for ulcer healing rate, ulcer recurrence, leg salvage rate and major amputation.

Results: Out of 50 participants in 52\% direct revascularization was done. Base line characteristics of both the groups were comparable except gender (where proportion of females was higher in indirect group), CKD, smoking, UTCWS grade of ulcer which were more in direct group. Ulcer predominantly affected toes (70\%) and Anterior Tibial angiosome was the most common (50\%) angiosome involved by clinical classification. Most common affected arterial segment pattern by Peripheral angiogram was multi segmental followed by infra popliteal disease. In $78.3 \%$ of cases ulcer healed at 6 months in the indirect group whereas $57.7 \%$ patients had healed ulcers at 6 months in the direct group ( $\mathrm{P}$ value $=0.12$ ). Female gender, $\mathrm{CKD}$, smoking and ulcer grade found to have no association with healing at 6 months. No significant difference was found in leg salvage rate, ulcer recurrence and major amputation.

Conclusions: Endovascular revascularization is a good modality to reduce morbidity in diabetic foot ulcer patients. There was no significant difference in outcome between these two groups.
\end{abstract}

Keywords: Peripheral occlusive arterial disease, Diabetic foot ulcer, Angiosome, Peripheral percutaneous trans luminal angioplasty, Peripheral angiogram

\section{INTRODUCTION}

Foot ulcers are common in diabetic population. Ischemia, neuropathy, and infection forms etiological triad. Among these three, occlusive disease of the infra popliteal arteries are the most important factor preventing healing of diabetic foot ulcers. ${ }^{1,2}$ Despite achievement of revascularization several factors cause delayed healing. Inadequate arterial flow to specific ulcer area may be one of the reason for delayed wound healing. ${ }^{3}$ Ian Taylor et al put forward angiosome concept, which states specific source artery supplies specific areas of foot. This concept is adapted in vascular revascularization and multiple studies about wound healing have been published over the last decade in vascular literature showed promising results in terms of ulcer healing rates and amputation free survival. But in order to open a specific source artery to ulcer area requires more time, more skills, more contrast 
and prolongs procedure time. This study is an attempt to know whether significant advantage exist for angiosome guided revascularization over non-angiosome guided revascularization.

\section{METHODS}

It's a prospective observational study conducted in our institution from October 2013 to October 2015 and included 50 foot ulcer patients with POVD who undergoes endovascular revascularization. The aim of our study was to evaluate the outcome in angiosome based revascularization in diabetic foot ulcer.

\section{Inclusion criteria}

Study population should satisfy following criteria

- Patients with diabetic foot ulcer having peripheral occlusive arterial disease (POAD)

- Patients who underwent percutaneous trans luminal angioplasty (PTA).

\section{Exclusion criteria}

- Patients who didn't give consent for the study

- Patient who underwent revision surgery

\section{Method of data collection}

Patients presenting with diabetic foot ulcer and POAD will be properly scrutinized with.

- Detailed history

- Clinical examination including each arterial pulsation

- Extent of tissue loss

- Duplex ultra sound imaging

- Peripheral angiogram

- Vascular surgeon opinion whether intervention indicated or not

As a result of an unclear distribution of the borderlines between angiosome, due to the existence of more than one scheme, we decided to adopt the general scheme of angiosome distribution, in which borderlines between angiosome match those outlined in the recent publication, "Long-term results of direct and indirect endovascular revascularization based on the angiosome concept in patients with critical limb ischemia presenting with isolated below-the-knee lesions "by Osamu Iida et al. Schematic diagram is shown in (Figure 1).

Before intervention first confirms the location of nonhealing ulcer by clinical examination and angiosome based favorable target lesion by peripheral angiogram. Per operatively we tried for an angiosome based intervention of the target lesion. If angiosome based straight line is obtained, patient is included in direct group. If angiosome based target lesion treatment is unsuccessful, a non angiosome based lesion will be treated and patient will be included in indirect group. In this way patients underwent endovascular intervention divided into two groups.

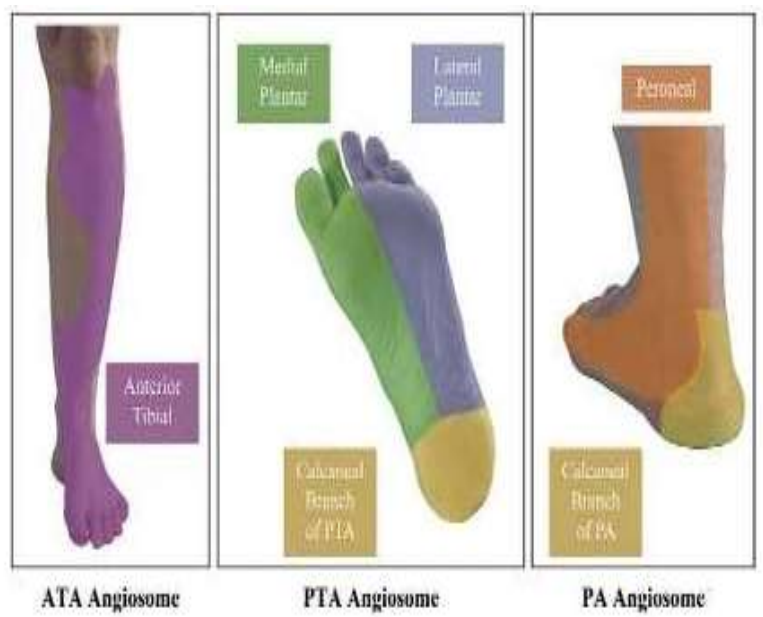

Figure 1: Schematic representation of the angiosomes of foot.

Antiplatelet therapy with Aspirin (150 mg daily) started prior to PTA and Clopidogrel $(150 \mathrm{mg})$ started after the procedure. Clopidogrel and Aspirin continued till ulcer heals and aspirin continued for life long. Local wound care chosen depending upon characteristics of each lesion.

All patients were followed for 6 months, at 1 week, 1 month, $3^{\text {rd }}$ month and $6^{\text {th }}$ months. During follow up patients were examined regarding status of wound, peripheral pulses and appropriate wound care was given. For this study, follow-up ended 6 months after the primary PTA, or death, whichever occurred first. An adverse event like major amputation (proximal to ankle level) was noted. Outcome measures of ulcer healing time, legs salvaged, and ulcer recurrence were looked into.

\section{Parameters studied are}

- Ulcer healing rate

- Ulcer recurrence

- Leg salvage rate

- Patients undergoing major amputation

\section{Statistical analysis}

Data was entered in Microsoft Excel and analysis was done using SPSS software (Trial Version 22). Descriptive analysis was done. The association between the type of revascularization done based on angiosome concept and various outcome parameters were looked into using ' $t$ ' test or Chi square test . 


\section{RESULTS}

A total of 50 diabetic foot ulcer with PVD who underwent endovascular revascularization to lower limb were included in this study. Direct flow to the foot ulcer based on the angiosome principle was achieved in 26 legs $(52 \%)$ and direct perfusion was not achieved in 24 legs $(48 \%)$.

\section{Gender Distribution}

Indirect group had more number of female patients 7 out of $24(29 \%)$ whereas only 2 out of 26 patients in direct group.

\section{Age Distribution}

Mean age of participants in direct group was 64.0 \pm 9.0 years whereas that of participants in indirect group was $65.3 \pm 11.5$ years. Indirect group had older patients (Table $1)$.

Table 1: Age distribution in both groups.

\begin{tabular}{|c|c|c|c|c|c|c|}
\hline \multirow{2}{*}{$\begin{array}{l}\text { Age } \\
\text { years }\end{array}$} & \multicolumn{2}{|c|}{ Indirect } & \multicolumn{2}{|r|}{ Direct } & \multirow{2}{*}{$\chi^{2}$} & \multirow{2}{*}{$\mathbf{P}$} \\
\hline & $\mathrm{Cou}$ & nt $\%$ & Count & $\%$ & & \\
\hline$<65$ & 13 & 54.2 & 13 & 50.0 & \multirow{3}{*}{0.09} & \multirow{3}{*}{0.768} \\
\hline$\geq 65$ & 11 & 45.8 & 13 & 50.0 & & \\
\hline $\bar{M}$ ean \pm SD & & $3 \pm 11.5$ & 64.0 & \pm 9.0 & & \\
\hline
\end{tabular}

Both the groups were not significantly different in terms of age of participants.

\section{BMI}

Mean body mass index of direct group was $21.5 \pm 2.6$ $\mathrm{kg} / \mathrm{m}^{2}$ that of indirect group was $22.2 \pm 2.5 \mathrm{~kg} / \mathrm{m}^{2}$ (Table $2)$.

Table 2: Comparison of groups based on BMI.

\begin{tabular}{|c|c|c|c|c|c|c|}
\hline \multirow{2}{*}{$\begin{array}{l}\text { BMI } \\
\left(\mathrm{kg} / \mathrm{m}^{2}\right)\end{array}$} & \multicolumn{2}{|c|}{ Indirect } & \multicolumn{2}{|c|}{ Direct } & \multirow{2}{*}{$x^{2}$} & \multirow{2}{*}{$\mathbf{p}$} \\
\hline & Count & $\%$ & Count & $\%$ & & \\
\hline $\begin{array}{l}\text { Under } \\
\text { weight }\end{array}$ & 1 & 4.2 & 4 & 15.4 & \multirow{3}{*}{2.62} & \multirow{3}{*}{0.270} \\
\hline $\begin{array}{l}\text { Normal } \\
\text { weight }\end{array}$ & 21 & 87.5 & 18 & 69.2 & & \\
\hline $\begin{array}{l}\text { Over } \\
\text { weight }\end{array}$ & 2 & 8.3 & 4 & 15.4 & & \\
\hline Mean \pm SD & 22.2 & $2 \pm 2.5$ & $21.5 \pm 2$ & 2.6 & & \\
\hline
\end{tabular}

There was no significant difference in BMI of both groups.

\section{Addictions}

Depicts the distribution of participants according to smoking behavior (Table 3).
Table 3: Distribution according to smoking.

\begin{tabular}{|lllll|}
\hline \multirow{2}{*}{ Smoking } & \multicolumn{2}{c}{ Indirect } & \multicolumn{2}{c|}{ Direct } \\
\cline { 2 - 5 } & Count & $\%$ & Count & $\%$ \\
\hline No & 13 & 54.2 & 7 & 26.9 \\
\hline Yes & 11 & 45.8 & 19 & 73.1 \\
\hline
\end{tabular}

30 out of the 50 participants were smokers. The number of smokers in direct group was significantly higher $\left(X^{2}=\right.$ $3.86^{*}, \mathrm{P}=0.049$ ).

\section{Comorbidities}

All the participants in both the groups were diabetic. Both groups were comparable in terms of comorbidities. CKD which is a well-established factor for non-healing ulcer was present more in direct group. 5 patients out of 26 (19.2\%) against a single patient in indirect group and he was on hemodialysis. But this was not statistically significant (P value 0.101) (Table 4).

Table 4: Distribution of participants based on comorbidities.

\begin{tabular}{|c|c|c|c|c|c|c|}
\hline \multirow{2}{*}{$\begin{array}{l}\text { Comorbid- } \\
\text { ities }\end{array}$} & \multicolumn{2}{|c|}{ Indirect } & \multicolumn{2}{|c|}{ Direct } & \multirow{2}{*}{$x^{2}$} & \multirow{2}{*}{$\mathbf{p}$} \\
\hline & Count & $\% \mathrm{C}$ & unt & $\%$ & & \\
\hline DM & 24 & 100 & 26 & 100 & & \\
\hline Hypertension & 12 & 50.0 & 17 & 65.4 & 1.21 & 0.271 \\
\hline Hyperlipidemia & 12 & 50.0 & 16 & 61.5 & 0.67 & 0.412 \\
\hline $\begin{array}{l}\text { Chronic } \\
\text { Kidney Disease }\end{array}$ & e & 4.2 & 5 & 19.2 & 2.68 & 0.101 \\
\hline $\begin{array}{l}\text { Coronary } \\
\text { Artery Disease }\end{array}$ & 6 & 25.0 & 10 & 38.5 & 1.04 & 0.308 \\
\hline $\begin{array}{l}\text { Cerebral } \\
\text { Vascular } \\
\text { Disease }\end{array}$ & 3 & 12.5 & 0 & 0.0 & 3.46 & 0.063 \\
\hline $\begin{array}{l}\text { Chronic } \\
\text { Obstructive } \\
\text { Pulmonary } \\
\text { Disease }\end{array}$ & 3 & 12.5 & 1 & 3.8 & 1.27 & 0.260 \\
\hline
\end{tabular}

Table 5: Distribution according to duration of diabetes mellitus.

\begin{tabular}{|l|crll|}
\hline $\begin{array}{l}\text { Duration of } \\
\text { diabetes mellitus } \\
\text { (in years) }\end{array}$ & \multicolumn{2}{c}{ Count } & $\%$ & \multicolumn{2}{c|}{ Count } & $\%$ \\
\hline$\leq 10$ & 7 & 29.2 & 6 & 23.1 \\
\hline $11-15$ & 5 & 20.8 & 6 & 23.1 \\
\hline $16-20$ & 7 & 29.2 & 7 & 26.9 \\
\hline$>20$ & 5 & 20.8 & 7 & 26.9 \\
\hline Mean \pm SD & $16.2 \pm 6.5$ & \multicolumn{2}{c|}{$18.5 \pm 8.0$} \\
\hline
\end{tabular}

Mean duration of diabetes in direct group was $18.5 \pm 8.0$ years and in indirect group was a $16.2 \pm 6.5$ year. Patients in direct group were having longer duration of diabetes. 


\section{Location of ulcer}

Majority of ulcer in this study were located in toe (70\%), followed by plantar aspect of foot $(14 \%)$. This shows that ischemic ulcers have a tendency to occur distally (Figure 2).

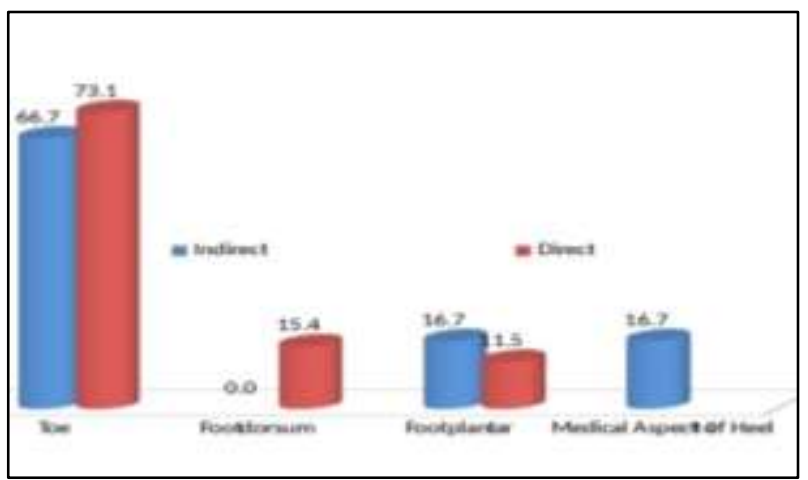

Figure 2: Comparison of group based on ulcer location.
$73.1 \%$ of direct group had ulcers in distally in toes whereas $66.7 \%$ of indirect group were having ulcers in the toe.

\section{Characteristics of ulcer}

There was a significant ( $p$ value 0.032 ) difference between the characteristics of ulcer in both groups. Majority of the ulcer direct group (73\%) were belonging to UTCWS grade 3 (wound penetrating to bone and joint) whereas majority of the ulcer in the indirect group were belonging to UTCWS grade 2 (wound penetrating to tendon or capsule).

$69.2 \%$ of direct group belonged to stage D (both infection and ischemia) when compared to $62.5 \%$ in indirect group. As shown in (Table 6) ulcers of direct group were having higher grade of UTCW system and hence had bad prognosis. This data shows that ulcers of direct group were having higher grade of UTCW system and hence bad prognosis.

Table 6: Comparison of both groups based on characteristics of wound.

\begin{tabular}{|llllllll|}
\hline \multirow{2}{*}{ Characteristics of wound } & & \multicolumn{3}{c}{ Indirect } & \multicolumn{1}{c}{ Direct } & \multirow{2}{*}{$\chi^{2}$} & p \\
\hline \multirow{3}{*}{ UTCWS Classification } & & Count & Percent (\%) & Count & Percent (\%) & & \\
& Grade 1 & 4 & 16.7 & 3 & 11.5 & \multirow{2}{*}{$6.91 *$} & 0.032 \\
\cline { 2 - 8 } & Grade 2 & 11 & 45.8 & 4 & 15.4 & \\
\cline { 2 - 7 } & Grade 3 & 9 & 37.5 & 19 & 73.1 & & \\
\hline \multirow{2}{*}{ UTCWS Classification } & Stage C & 9 & 37.5 & 8 & 30.8 & \multirow{2}{*}{0.25} & 0.616 \\
\cline { 2 - 7 } & Stage D & 15 & 62.5 & 18 & 69.2 & \\
\hline
\end{tabular}

\section{Angiosome affected}

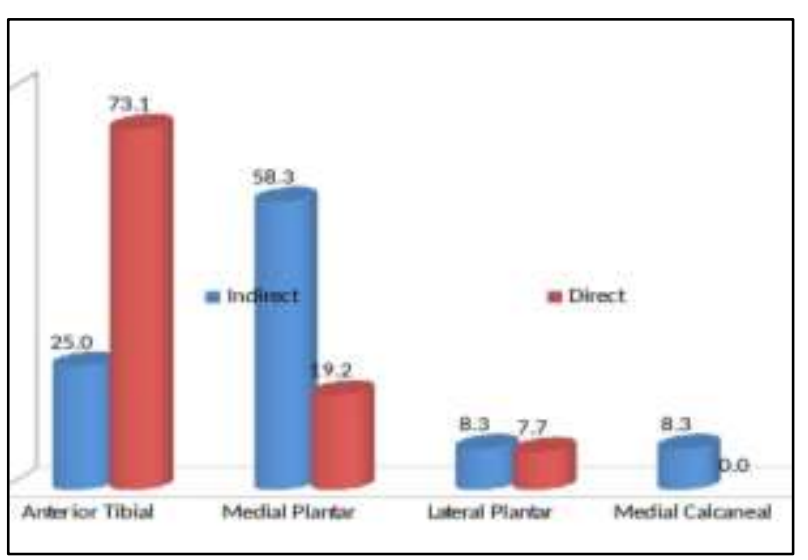

Figure 3: Distribution of angiosome affected in both group.

Angiosome fed by anterior tibial was the most common angiosome affected which constituted 25 out of the total 50 cases $(50 \%)$ followed by medial plantar angiosome 19 cases $(20 \%)$, lateral plantar artery 4 cases $(8 \%)$ and 2 cases $(4 \%)$ belonged to medial calcaneal angiosome. None of cases were belonging to angiosome fed by peroneal artery. It shows that peroneal artery is the last artery to be involved in diabetic foot with pad (Figure 3).

\section{Affected arterial segment}

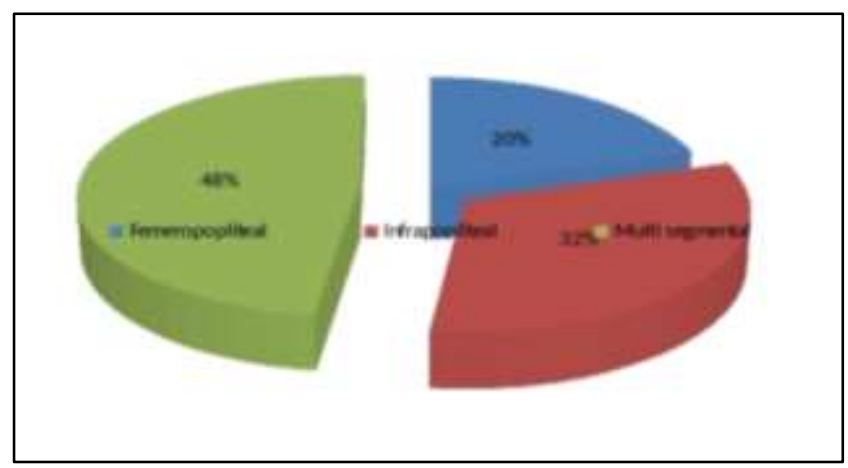

Figure 4: Pattern of affected arterial segment in this study. 
When analysing involved segment of arteries, most common pattern found was multisegmental involvement $48 \%$ of cases whereas involvement of infra popliteal segment and femeropopliteal segment were $32 \%$ and $20 \%$ respectively (Figure 4 ).

This shows that involvement peripheral vessels in pad in diabetic foot is multisegmental $48 \%$ (both femeropopliteal and infra popliteal) and tibioperoneal trunk is more affected than femeropopliteal segment (32\% versus $20 \%$ ).

Percutaneous trans luminal angioplasty was commonly done to superficial femoral artery in indirect group whereas anterior tibial was the commonly treated artery in direct group.

The various outcome parameter studied in this study are ulcer healing at 6 months, recurrent ulceration and Major Amputation.

\section{Ulcer healed at 6 months}

Reveals that in $78.3 \%$ cases ulcer healed at 6 months in the indirect group whereas $57.7 \%$ patients had healed ulcers at 6 months in the direct group. This difference in proportion wasn't found to be significant $(\mathrm{P}$ value $=0.12$ ) (Table 7).

Table 7: Comparison of groups based on proportion of ulcer healed at 6 months.

\begin{tabular}{|c|c|c|c|c|c|c|}
\hline \multirow{2}{*}{$\begin{array}{l}\text { Whether } \\
\text { healed at } \\
6 \text { months }\end{array}$} & \multicolumn{2}{|c|}{ Indirect } & \multicolumn{2}{|c|}{ Direct } & \multirow[b]{2}{*}{$x^{2}$} & \multirow[b]{2}{*}{$\mathbf{p}$} \\
\hline & Count & $\%$ & Count & $\%$ & & \\
\hline No & 5 & 21.7 & 11 & 42.3 & \multirow{2}{*}{2.35} & \multirow{2}{*}{0.125} \\
\hline Yes & 18 & 78.3 & 15 & 57.7 & & \\
\hline
\end{tabular}

Ulcer healing time

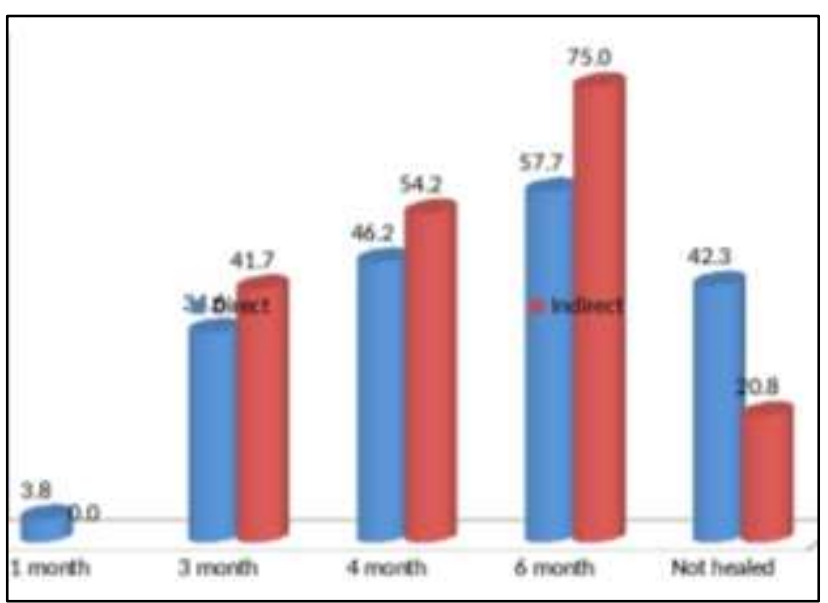

Figure 5: Comparison ulcer healing time in both group.
One death occurred in 1st month in indirect group so he was excluded in calculating healing rate. 33 patients out of 49 cases $(67.3 \%)$ had completely healed wound at 6 months of follow up. 5 out of 23 patients in indirect groups were having persistent wound at 6 months $(21.7 \%)$. Direct group had 11 out of $26(42.3 \%)$ wound that was not healed at the end of 6 month, though this was not statistically not significant ( $P$ value 0.125 ) (Figure 5).

Association of Gender with ulcer healing at 6 months

Table 8: Comparison of whether healed at 6 months based on gender.

\begin{tabular}{|c|c|c|c|c|c|c|}
\hline \multirow[t]{2}{*}{ Sex } & \multicolumn{2}{|c|}{$\begin{array}{l}\text { Ulcer not } \\
\text { healed }\end{array}$} & \multicolumn{2}{|c|}{$\begin{array}{l}\text { Ulcer healed } \\
\text { at } 6 \text { months }\end{array}$} & \multirow{2}{*}{$x^{2}$} & \multirow{2}{*}{$\mathbf{p}$} \\
\hline & Count & $\%$ & Count & $\%$ & & \\
\hline Male & 13 & 32.5 & 27 & 67.5 & \multirow{2}{*}{0.00} & \multirow{2}{*}{0.962} \\
\hline Female & 3 & 33.3 & 6 & 66.7 & & \\
\hline
\end{tabular}

Out of nine females six $(66 \%)$ had healed wound at 6 months, whereas $67.5 \%$ males achieved ulcer healing at 6 months. No significant association between ulcer healing at 6 months and gender.

Association of smoking behaviour with ulcer healing at 6 months

Table 9: Comparison of whether healed at 6 months based on smoking.

\begin{tabular}{|c|c|c|c|c|c|c|}
\hline \multirow[t]{2}{*}{$\begin{array}{l}\text { Smok- } \\
\text { ing }\end{array}$} & \multicolumn{2}{|c|}{$\begin{array}{l}\text { Ulcer not } \\
\text { healed at } 6 \\
\text { month }\end{array}$} & \multicolumn{2}{|c|}{$\begin{array}{l}\text { Ulcer } \\
\text { healed at } 6 \\
\text { month }\end{array}$} & \multirow[t]{2}{*}{$x^{2}$} & \multirow[t]{2}{*}{$\mathbf{p}$} \\
\hline & Count & $\%$ & Count & $\%$ & & \\
\hline No & 6 & 37.5 & 13 & 39.4 & \multirow{2}{*}{0.02} & \multirow{2}{*}{0.898} \\
\hline Yes & 10 & 62.5 & 20 & 60.6 & & \\
\hline
\end{tabular}

Out of 30 smokers 20 had healed wound at 6 months. No significant association between ulcer healing at 6 months and smoking behaviour.

\section{Association of CKD with ulcer healing at 6 months}

Table 10: Comparison of whether healed at 6 months based on chronic kidney disease.

\begin{tabular}{|c|c|c|c|c|c|c|}
\hline \multirow[t]{2}{*}{$\begin{array}{l}\text { Chronic } \\
\text { Kidney } \\
\text { Disease }\end{array}$} & \multicolumn{2}{|c|}{$\begin{array}{l}\text { Ulcer not } \\
\text { healed at } 6 \\
\text { month }\end{array}$} & \multicolumn{2}{|c|}{$\begin{array}{l}\text { Ulcer healed } \\
\text { at } 6 \text { month }\end{array}$} & \multirow[t]{2}{*}{$x^{2}$} & \multirow[t]{2}{*}{$\mathbf{P}$} \\
\hline & Count & $\%$ & Count & $\%$ & & \\
\hline No & 12 & 75.0 & 31 & 93.9 & 3.6 & 0.0 \\
\hline Yes & 4 & 25.0 & 2 & 6.1 & 0 & 58 \\
\hline
\end{tabular}

Out of six CKD patients 4 had non healing ulcer at 6 months $(P=0.058)$. No significant association between ulcer healing at 6 months and CKD. 
Association of ulcer grade with ulcer healing at 6 months

Table 11: Comparison of whether healed at 6 months based on UTCWS classification.

\begin{tabular}{|c|c|c|c|c|c|c|}
\hline \multirow{2}{*}{$\begin{array}{l}\text { UTCWS } \\
\text { Classificati } \\
\text { on-ion }\end{array}$} & \multicolumn{2}{|c|}{$\begin{array}{l}\text { Ulcer not } \\
\text { healed at } 6 \\
\text { month }\end{array}$} & \multicolumn{2}{|c|}{$\begin{array}{l}\text { Ulcer healed } \\
\text { at } 6 \text { month }\end{array}$} & \multirow[t]{2}{*}{$x^{2}$} & \multirow[t]{2}{*}{$\mathbf{p}$} \\
\hline & Count & $\%$ & Count & $\%$ & & \\
\hline Grade 1 & 2 & 12.5 & 5 & 15.2 & \multirow{3}{*}{1.95} & \multirow{3}{*}{0.378} \\
\hline Grade 2 & 3 & 18.8 & 12 & 36.4 & & \\
\hline Grade 3 & 11 & 68.8 & 16 & 48.5 & & \\
\hline
\end{tabular}

27 patients had grade 3 UTCWS ulcer and 16 patients $(59.2 \%)$ had healed ulcer at 6 months $(P=0.37)$ No significant association between ulcer healing at 6 months and ulcer grade.

This proves that ulcer healing at 6 months had no significant association with CKD, smoking, or ulcer grade based on UTCW system.

Recurrent ulcers were present in $4 \%$ of cases $(8.16 \%)$ of which three was belonging to direct group. This finding also not statistically significant $(\mathrm{P}=0.61)$.

Table 12: Comparison of two groups based on recurrent ulcers.

\begin{tabular}{|llllll|}
\hline Recurrent & \multicolumn{2}{c}{ Indirect } & \multicolumn{2}{c|}{ Direct } & \multirow{2}{*}{ \#\# } \\
\cline { 1 - 5 } ulcers & Count & $\%$ & Count & $\%$ & \\
\hline No & 22 & 95.7 & 23 & 88.5 & 0.61 \\
\cline { 1 - 5 } Yes & 1 & 4.3 & 3 & 11.5 & 0 \\
\hline
\end{tabular}

Inference no significant advantage for direct revascularization in preventing recurrent ulceration over indirect revascularization.

Major Amputation out of 50 participant's only one participant $(2 \%)$ underwent major amputation (proximal to ankle level). So we can infer that no significant advantage for direct revascularization in terms of major amputation.

Leg salvage rate 49 legs out of 50 were able to salvage at end of 6 months $(98 \%)$. No significant between two groups in Leg salvage rate. We can infer that endovascular revascularization is a good modality to reduce morbidity in diabetic foot ulcer patients.

Table 13: Death within 6 months.

\begin{tabular}{|llllll|}
\hline & \multicolumn{2}{c}{ Indirect } & \multicolumn{2}{c}{ Direct } & p\# \\
& Count & $\%$ & Count & $\%$ & \\
\hline $\begin{array}{l}\text { Death within } \\
6 \text { months }\end{array}$ & 3 & 12.5 & 1 & 3.8 & 0.340 \\
\hline
\end{tabular}

Deaths total 4 deaths occurred in study sample. 3 deaths occurred in indirect group one was during $4^{\text {th }}$ month post procedure due to sepsis from wound and he underwent major amputation also. Other two deaths were due to COPD exacerbation in $1^{\text {st }}$ month and CKD respectively. One death in direct group was due to CKD during 6th month post procedure. So we can infer that there is no significant difference in death rate between two groups $(\mathrm{P}$ $=0.34)$.

\section{DISCUSSION}

Diabetic foot ulcers are very common complication in diabetic patients and important cause of morbidity to patient and affect quality of life. Ischemia forms a major risk factor for a non-healing ulcer. Even after successful revascularization these ulcers show delay in healing. Based on studies by Ian Taylor who proposed angiosome concept, it is said that non achievement of direct flow to ulcer area may be a reason for this.

A prospective observational study was done which included 50 diabetic foot ulcer patient who underwent endovascular revascularization (PTA) in our institution during the period October 2013 to March 2015 and they were followed up for 6 months to look for ulcer healing rate, ulcer recurrence, leg salvage rate and major amputation.

A total of 50 diabetic foot ulcer with PAD who underwent endovascular revascularization to lower limb were included in this study. Direct flow to the foot ulcer based on the angiosome principle was achieved in 26 legs $(52 \%)$. Indirect group had more number of female patients 7 out of $24(29 \%)$ whereas only 2 out of 26 patients in direct group. Mean age of participants in direct group was $64.0 \pm 9.0$ years whereas that of participants in indirect group was $65.3 \pm 11.5$ years. Mean Body mass index of direct group was $21.5 \pm 2.6 \mathrm{~kg} / \mathrm{m}^{2}$ that of indirect group was $22.2 \pm 2.5 \mathrm{~kg} / \mathrm{m}^{2}$. 30 out of the 50 participants were smokers. The number of smokers in direct group was significantly higher $(\mathrm{P}=0.049)$. All the participants in both the groups were diabetic. Base line characteristics of both the groups were comparable except gender (where proportion of females was higher in indirect group), CKD, smoking, UTCWS grade of ulcer which were more in direct group. 5 patients out of 26 (19.2\%) against a single patient in indirect group and he was on hemodialysis.

Majority of ulcer in this study were located in toe (70\%), followed by plantar aspect of foot (14\%).This was in accordance with the literature. ${ }^{5,6}$ There was a significant ( $p$ value 0.032 ) difference between the characteristics of ulcer in both groups. Majority of the ulcer direct group (73\%) were belonging to UTCWS grade 3 whereas majority of the ulcer in the indirect group were belonging to UTCWS grade 2, $69.2 \%$ of direct group belonged to stage D (both infection and ischemia). Angiosome fed by anterior tibial was the most common angiosome affected which constituted 25 out of the total 50 cases $(50 \%)$ followed by medial plantar angiosome 19 cases $(20 \%)$, 
lateral plantar artery 4 cases (8\%) and 2 cases (4\%) belonged to medial calcaneal angiosome. When analyzing involved segment of arteries, most common pattern found was multi segmental involvement $48 \%$ of cases whereas involvement of infra popliteal segment and femeropopliteal segment were $32 \%$ and $20 \%$ respectively. This is in accordance with Edmon et al observation. $^{7}$

The various outcome parameter studied in this study are ulcer healing at 6 months, recurrent ulceration and major amputation. In $78.3 \%$ cases ulcer healed at 6 months in the indirect group whereas $57.7 \%$ patients had healed ulcers at 6 months in the direct group. This difference in proportion wasn't found to be significant $(\mathrm{P}$ value $=$ 0.12 ). No significant association was found between ulcer healing at 6 months and gender $(\mathrm{P}$ value $=0.962)$. Out of 30 smokers 20 had healed wound at 6 months. No significant association between ulcer healing at 6 months and smoking behavior was seen in this study $(\mathrm{P}=0.89)$. Out of six CKD patients 4 had non healing ulcer at 6 months $(\mathrm{P}=0.058)$. This study couldn't find any significant association between ulcer healing at 6 months and CKD. 27 patients had grade 3 UTCWS ulcer and 16 patients $(59.2 \%)$ had healed ulcer at 6 months $(\mathrm{P}=0.37)$. This proves that ulcer healing at 6 months had no significant association with CKD, smoking, or ulcer grade based on UTCW system.

Recurrent ulcers were present in $4 \%$ of cases $(8.16 \%)$ of which three was belonging to direct group. This finding is also not statistically significant $(\mathrm{P}=0.61)$. Out of 50 participants only one participant $(2 \%)$ underwent major amputation (proximal to ankle level). So we can infer that no significant advantage for direct revascularization in terms of major amputation. 49 legs out of 50 were able to salvage at end of 6 months $(98 \%)$. No significant between two groups in leg salvage rate. Total 4 deaths occurred in study sample. 3 death occurred in indirect group ,one was during $4^{\text {th }}$ month post procedure due to sepsis from wound and he underwent major amputation also .Other two deaths was due to COPD exacerbation in 1st month and CKD in $5^{\text {th }}$ month respectively. One death in direct group was due to CKD during $6^{\text {th }}$ month post procedure.

Similar ulcer healing rates are reported by Deguchi et al who included 66 legs and a similar healing rate in both group ( $73 \%$ in DR versus $72 \%$ in IR). ${ }^{8}$ Although apparent better healing seen in indirect group, it may be due to the fact that higher number of smokers, CKD patients and grade 3 ulcer in direct group, which are known risk factors for non-healing in a diabetic foot. Kabra et al and Azuma et al provided a similar leg salvage rate at 6 months post procedure we can conclude that, there is no significant advantage of achieving direct pulsatile blood flow to an ischemic angiosome during endovascular revascularization in diabetic foot ulcers over revascularization in which direct flow can't be attained in terms ulcer healing rate, limb salvage or survival rate.
But we need a large multicenteric trials to refute the Angiosome concept.

The limitations of this study was total number of patient here is only 50. We need large randomized control studies to validate or refute the angiosome concept. Due to multiple anatomical variations in the foot arteries, the general scheme of angiosomal distribution cannot used in the case of every patient. The diversity of the distribution is well demonstrated in Attinger's study from 2006. ${ }^{12,13}$ Diabetic patients may present with a multitude of wounds that are heterogeneous in morphology and topography. So it was difficult to assign patients into a particular angiosome.

\section{CONCLUSION}

Endovascular revascularization is a good modality for treating ischemic diabetic foot ulcers to reduce the morbidity. From this study we can conclude that, there is no significant advantage of achieving direct pulsatile blood flow to an ischemic angiosome during endovascular revascularization in diabetic foot ulcers when compared to revascularization in which direct flow can't be attained in terms ulcer healing rate, limb salvage or survival rate. But we need large multicenteric trials to refute the angiosome concept.

Funding: No funding sources Conflict of interest: None declared

Ethical approval: The study was approved by the institutional ethics committee

\section{REFERENCES}

1. Brownrigg JRW, Apelvist J, Bakker K, Schaper NC, Hinchliffe RJ. Evidence-based management of PAD and the diabetic foot. Eur. J. Vasc. Endovasc. Surg. Elsevier Ltd. 2013;45(6):673-81 .

2. Graziani L, Silvestro A, Bertone V, Manara E, Andreini R, Sigala A, et al. Vascular involvement in diabetic subjects with ischemic foot ulcer: a new morphologic categorization of disease severity. Eur. J Vasc Endovasc Surg. 2007;33(4):453-60.

3. Prompers L, Schaper N, Apelqvist J, Edmonds M, Jude E, Mauricio D, et al. Prediction of outcome in individuals with diabetic foot ulcers: focus on the differences between individuals with and without peripheral arterial disease. The Eurodiale Study. Diabetologia. 2008;51:747-55.

4. Iida O, Soga Y, Hirano K, Kawasaki D, Suzuki K, Miyashita Y, et al. Long-term results of direct and indirect endovascular revascularization based on the angiosome concept in patients with critical limb ischemia presenting with isolated below-the-knee lesions. J Vasc Surg Elsevier Inc. 2012;55(2):36370.

5. Apelqvist J, Castenfors J, Larsson J. Wound classification is more important than site of 
ulceration in the outcome of diabetic foot ulcers. Diabet Med.1989;6:526-30.

6. Reiber GE, Lipsky BA, Gibbons GW. The burden of diabetic foot ulcers. Am J Surg. 1998;176(2A):5S-10S.

7. Edmonds ME, Morrison, Laws JW, Watkins PJ. Medical arterial calcification and diabetic neuropathy. British Medical Journal. 1982;284:92930.

8. Deguchi J, Kitaoka T, Yamamoto K, Matsumoto H, Sato O. Impact of angiosome on treatment of diabetic ischaemic foot with paramalleolar bypass. $\mathrm{J}$ Jpn Coll Angiol. 2010;50:687-91.

9. Moss SE, Klein R, Klein BEK. The prevalence and incidence of lower extremity amputation in a diabetic population. Arch Intern Med. 1992;152:610-6.

10. Kabra A, Suresh KR, Vivekanand V, Vishnu M, Sumanth R, Nekkanti M. Outcomes of angiosome and non-angiosome targeted revascularization in critical lower limb ischemia. J Vasc Surg. Elsevier Inc. 2013;57(1):44-9.

11. Azuma N, Uchida H, Kokubo T, Koya A, Akasaka N, Sasajima T. Factors influencing wound healing of critical ischaemic foot after bypass surgery: is the angiosome important in selecting bypass target artery? European Journal of Vascular and Endovascular Surgery. 2012;43(3):322-8.

12. Houlind $\mathrm{K}$, Christensen J. The role of the angiosome model in treatment of critical limb ischemia, artery bypass. Dr Wilbert S. Aronow (Ed.). 2013:425-34.

13. Attinger CE, Evans KK, Cooper P. Angiosomes of the foot and ankle and clinical implications for limb salvage: reconstruction, incisions, and revascularization. Plast Reconstr Surg. 2006;117:261S-93S.

Cite this article as: Rajendran S, Thottiyil SM, Karatparambil AA, Nadakkavil MRM, Thamaran R, Kattoor TT. Evaluation of angiosome based revascularization in diabetic foot ulcers. Int Surg J 2016;3:721-8. 